\title{
Transvenous Phrenic Nerve Stimulation and Positive Airway Pressure devices for Central Sleep Apnea in Patients with Heart Failure with Reduced Ejection Fraction: A Network Meta-analysis
}

IMRAN HASAN IFTIKHAR ( $\square$ Imran.hasan.iftikhar@emory.edu )

Emory University School of Medicine https://orcid.org/0000-0001-5102-5193

\section{Rami N Khayat}

University of California Irvine College of Medicine: University of California Irvine School of Medicine

Research Article

Keywords: Central sleep apnea, Transvenous Phrenic Nerve Stimulation, Network Meta-analysis

Posted Date: February 16th, 2021

DOI: https://doi.org/10.21203/rs.3.rs-184986/v1

License: (c) (1) This work is licensed under a Creative Commons Attribution 4.0 International License.

Read Full License 


\section{Abstract}

Purpose: Adaptive servo-ventilation (ASV) is contraindicated for central sleep apnea (CSA) treatment in patients with heart failure with reduced ejection fraction (HFrEF) limiting treatment options. Though, continuous positive airway pressure (CPAP), bi-level PAP with back-up rate (BPAP-BUR) and transvenous phrenic nerve stimulation (TPNS) are alternatives, not much is known about their comparative efficacies, which formed the basis of this network meta-analysis, in which their effects on apnea hypopnea index (AHI) and subjective daytime sleepiness (based on Epworth sleepiness score (ESS)), were analyzed.

Methods: PubMed was searched for potentially includable randomized controlled trials and network meta-analysis was conducted in R program using package netmeta.

Results: Network meta-analysis showed no statistically significant differences between interventions in $\mathrm{AHI}$ reduction. In exploring heterogeneity, sensitivity analysis elicited statistically significant differences in AHI reduction between ASV and TPNS $(-18.30$ [-27.8; -8.79]), with BPAP-BUR $(-21.90[-30.79 ;-13.01])$ and CPAP (-23.10 [-29.22; -16.98]), favoring ASV. Of all the interventions, only TPNS showed a statistically significant decrease in ESS $(-3.70(-5.58 ;-1.82))$ when compared to guideline directed medical therapy (used as a common comparator across trials), while also showing significant differences when compared with ASV (-3.20 (-5.86; -0.54)), BPAP-BUR (-4.00 (-7.33; -0.68)), and CPAP (-4.45 (-7.75; -1.14)). Hasse diagram, accounting for both $\mathrm{AHI}$ and ESS as outcomes for relative hierarchy showed relative superiority of both ASV and TPNS over BPAP-BUR and CPAP.

Conclusions: Results indicate relative superiority of TPNS and ASV to BPAP-BUR and CPAP in their effects on AHI and ESS reduction in patients with CSA and HFrEF.

\section{Introduction}

Central sleep apnea (CSA) is characterized by temporary withdrawal of central (brainstem-driven) respiratory drive that results in the cessation of respiratory muscle activity and airflow. Patients with heart failure (HF) commonly have a form of CSA, called Cheyne-Stokes respiration (CSR) in which ventilatory instability produces a distinctive form of periodic breathing with recurring cycles of crescendodecrescendo ventilation with prolonged central apneas or hypopneas in between.[1] CSA-CSR occurs in up to $40 \%$ of patients with HF.[1,2] HF produces ventilatory control instability via several pathways that include pulmonary interstitial congestion, impaired cerebrovascular reactivity, caudal fluid shifts and prolonged circulation time and it is believed that the oscillation of the blood carbon dioxide levels around the apneic threshold appears to be the key factor in starting CSA and in perpetuating the ventilatory instability during sleep.[3] The repeated episodes of apnea in CSA, similar to OSA, are associated with hypoxemia, followed by reoxygenation and arousal in a cycle throughout the night, leading to frequent intermittent surges and upregulation of the sympathetic nervous system. In patients with HF sympathetic stimulation leads to further downstream effects such as tachycardia, peripheral vasoconstriction, sodium retention, and renin angiotensin-aldosterone system activation, all of which are associated with poor 
prognosis in patients with HF.[4,5] Optimization of HF therapy is the cornerstone in the management of CSA in HF patients, [6] as studies have shown that when HF is clinically improved, CSA too generally improves more or less $[7,8]$. Because CSA often persists despite aggressive treatment of HF, targeted treatment for CSA must be considered. Treatment options for CSA have included positive airway pressure (PAP) based devices including, adaptive servo ventilation (ASV), bi-level PAP with back-up respiratory rate (BPAP-BUR), continuous PAP (CPAP) and supplemental nocturnal oxygen, or medications like theophylline or acetazolamide. Studies evaluating oxygen and medications have been limited by their small sample sizes, thus limiting strong, evidence-based clinical recommendations. $[9,10]$ Transvenous phrenic nerve stimulation (TPNS) is the newest of the treatment options approved by the Food and Drug Administration for the treatment of moderate to severe CSA. TPNS primarily involves a neurostimulator with stimulation and sensing leads, implanted typically in the right pectoral region with the stimulation lead advanced into the right brachiocephalic vein to stimulate the phrenic nerve and a sensing lead which is typically placed in the azygos vein to sense respiration by thoracic impedance. The system is typically activated 1 month after implant and the device is further automatically programmed gradually over $\sim 12$ weeks to allow full diaphragmatic capture and resultant contraction during central apneas in sleep.[11] Since ASV is no longer indicated in CSA patients with left ventricular ejection fraction (LVEF) $<45 \%,[12]$ TPNS maybe a reasonable alternative to consider in these patients. Since TPNS has not been compared head-to-head with other PAP devices for CSA specifically in HF patients with reduced ejection fraction (HFrEF), we sought to determine their comparative efficacy using a network meta-analysis methodology. A network meta-analysis allows for comparisons of interventions that may not have been directly compared in head-to-head trials by simultaneously analyzing both direct comparisons of interventions within randomized controlled trials (RCTs) and indirect comparisons across multiple trials based on a common comparator.

\section{Methods}

The review was conducted in accordance with the Preferred Reporting Items for Systematic Reviews and Meta-Analyses (PRISMA) extension statement for network meta-analysis [13] as reported in Table E1.

\section{Search Strategy and Study Eligibility Criteria}

PubMed database was searched for RCTs from inception to November $20^{\text {th }}, 2020$. Inclusion and exclusion criteria for studies was similar to an already published direct pairwise meta-analysis.[14] Specifically, studies were considered for inclusion if they studied adult participants, aged $\geq 18$ years, diagnosed with primary CSA (with or without CSR) with an overall mean (or - 1 standard deviation (SD) from mean) apnea hypopnea index (AHI) cut-off of $>10$ events/hour, with central apneas comprising > $50 \%$ of all respiratory events, and participants' mean (or +2 SDs from mean) EF was $\leq 50 \%$. Additionally, studies were considered for inclusion only if they studied CPAP, ASV, BPAP-BUR or TPNS as interventions. Studies where data (of interest) was reported in median and inter-quartile range or presented in a way where mean and standard deviation or corresponding confidence intervals could not be ascertained were excluded from main analyses. From the included RCTs, those in the usual care or untreated control group 
were designated in this network meta-analysis as under 'guideline directed medical therapy' akin to the same methodology used in a previously published direct pairwise meta-analysis.[14]

\section{Data Extraction and Synthesis}

The studies were assessed for 'study quality' based on modified Cochrane methods. Data extracted from studies included first author's name, publication year, study design, population characteristics, AHI, Epworth sleepiness score (ESS). Data were first extracted on Microsoft Excel sheets and then on the working sheets of 'Comprehensive Meta-Analysis' (CMA version 2.2.064; Biostat, Englewood, N.J. U.S.A) software, to get uniform measures of changes as change scores computed as mean difference, corresponding 95\% confidence intervals ( $\mathrm{Cl}$ ) and standard errors (SE) between one intervention and control/active comparator. The R Foundation for Statistical Computing, Vienna, Austria) 'netmeta' package was used for performing all network meta-analysis functions within the 'frequentist' framework. This approach has been used in other network meta-analyses.[15,16] Results of network meta-analysis were presented as netgraphs or evidence plots (geometry of evidence), forest plots and network league tables, a square matrix showing all pairwise comparisons in a network meta-analysis. Inconsistency between direct and indirect/network meta-analysis was checked by 'netsplit' tables. The rankings for different PAP interventions was performed by ' $P$-scores'. P-scores are based solely on the point estimates and standard errors of the network estimates. They measure the extent of certainty that a treatment is better than another treatment, averaged over all competing treatments. This interpretation is comparable to that of the Surface Under the Cumulative RAnking curve (SUCRA).[17] Furthermore, 'Hasse' diagram was constructed using $\mathrm{R}$, which illustrates relations of different interventions in a partially ordered set with superior objects (interventions) located above inferior ones. Interventions not connected by arrows are considered incomparable, as individual rankings may go in opposite directions.[18] A 'comparison-adjusted' funnel plot to assess funnel plot asymmetry in network meta-analysis was constructed (for Eggers test of intercept, Begg and Mazumdar rank correlation test, and the ThompsonSharp tests).[19]

\section{Results}

Figure 1 shows the study selection process. A total of 9 RCTs were included in this network metaanalysis.[20-28] Table 1 lists the baseline characteristics of this study population. Risk of bias assessment is presented in table E2 in online resource/supplement.

The netgraphs or network evidence plots for the geometry of the evidence/studies (number of studies, participants and trials between comparisons) for AHI and ESS analyses are presented in figure 2 . In the network meta-analysis for AHI change, data from 8 studies[20-27] with a total of 648 participants was analyzed. Compared to GDMT, all interventions, ASV (-26.05 [-38.80; -13.31]), TPNS (-24.90 [-42.88; -6.92]), BPAP-BUR (-20.36 [-36.47; -4.25]) and CPAP (-16.01 [-25.42; -6.60]) showed statistically significant changes in $\mathrm{AHI}$ in their favor based on indirect (network) estimates (table 2 and figure $3 a$ ). There was no statistically significant difference between the interventions based on indirect (network) 
estimates. Statistical heterogeneity was detected in the AHI network meta-analysis $\left(\operatorname{tau}^{2}=72.6 ; P=\right.$ $88.5 \%$ ), as shown in table 2 . Sensitivity analysis by selectively excluding one study at a time from the overall analysis did not result in reduction of heterogeneity. Only when both the studies by O'Connor et al[27] and Fietze et al[22] were selectively excluded from the overall analysis, did the heterogeneity droptau $^{2}$ dropped to 0.01 and $R$ value to $0.2 \%$. Results are shown in table 2 and figure $3 \mathrm{~b}$. With this sensitivity analysis a statistically significant difference was found between ASV and all other active comparatorswith TPNS the difference was -18.30 [-27.8; -8.79], with BPAP-BUR -21.90 [-30.79; -13.01] and with CPAP -23.10 [-29.22; -16.98], as shown in table 2. While TPNS ranked higher than BPAP-BUR and CPAP (based on P-scores, as explained below), there were no statistically significant inter-treatment differences between TPNS and the latter.

In the analysis for change in ESS among all interventions, data from 6 RCTs[21,22,24,25,27,28] was analyzed comprising a total of 374 participants. Only TPNS showed a statistically significant decrease in ESS when compared to GDMT $(-3.70(-5.58 ;-1.82))$, based on both direct and indirect estimates. Results are shown in table 3 and figure 4 . Because no direct evidence existed between TPNS and other interventions, the difference between TPNS and other interventions is based solely on indirect (network) meta-analysis estimate, showing statistically significant reduction in ESS when compared with ASV (-3.20 (-5.86; -0.54)), BPAP-BUR (-4.00 (-7.33; -0.68)), and CPAP $(-4.45(-7.75 ;-1.14))$. There was no statistical heterogeneity detected in the ESS network meta-analysis ESS analysis $\left(\operatorname{tau}^{2}=0 ; R=0 \%\right.$ ).

Based on the netsplit table there was no statistical inconsistency detected between the network meta-analysis indirect estimates and direct meta-analysis estimates for AHI or ESS outcomes (netsplit tables in online resource/supplement).

$P$-score ranking, which is based solely on the point estimates and standard errors of the network estimates ranks ASV as first, TPNS as second, followed by BPAP-BUR and CPAP for the AHI network meta-analysis (the overall network ranking did not change with AHI sensitivity analysis) and ranks TPNS as first, ASV as second, followed by GDMT and then BPAP-BUR and CPAP coming last in the ESS network meta-analysis (figure 5). Hasse diagram accounting for both AHI and ESS as outcomes for relative hierarchy showed relative superiority of both ASV and TPNS over BPAP-BUR and CPAP (figure 5). When accounting for AHI sensitivity analysis the order in Hasse diagram did not change.

Publication bias for primary outcomes was assessed using funne/ plots, which on visual inspection showed no evidence of plot asymmetry (figure 6).

\section{Discussion}

The results of this network meta-analysis based on the Hasse diagram and P-scores suggests ASV and TPNS as the most effective treatment for CSA in patients with HFrEF, in terms of their effects on AHI and ESS. This conclusion is based on ranking from P-scores and Hasse diagrams which are based solely on effect size and SEs. It is also noteworthy to mention that in $\mathrm{AHI}$ reduction all treatments were superior to 
GDMT and in the overall analysis no inter-treatment differences were found. This analysis, however, showed high heterogeneity and upon exploring this heterogeneity with sensitivity analysis, two studies $(22,27)$ were found to be contributing to the overall heterogeneity. The sensitivity analysis showed a statistically significant difference between ASV and all others. In this sensitivity analysis, the study by O'Connor et al[27] stood out as one of the outliers and was excluded. This study had low statistical power primarily because after the results of the SERV-HF trial[12] became available further recruitment of participants was stopped. The other outlier was the study by Fietze et al[22] and while the study was similar to most other PAP intervention studies, in that the participants showed significant reductions in sleep-disordered breathing with PAP intervention along with an improvement in LVEF, the only difference between this study and others was that it reported respiratory disturbance index as opposed to $\mathrm{AHI}$ (which was reported in all the others) and this was defined by the authors as the sum of the CheyneStokes Apnea index, periodic breathing index, obstructive apnea index and mixed apnea index. With the sensitivity analysis, although the ranking of studies did not change, the differences between ASV and TPNS as well as its difference with BPAP-BUR and CPAP did become significant. It is important to note here that TPNS unlike its other active comparators (in this network meta-analysis) does not treat any obstructive apneas or obstructive hypopneas.[29] Despite this limitation of TPNS, it is remarkable that in the overall AHI reduction, TPNS out-performed BPAP-BUR and all other interventions in ESS improvement, actually meeting the minimal clinically important difference threshold with GDMT (based on both direct and indirect estimates) and also when compared with ASV, BPAP-BUR and CPAP (based on indirect estimates). It was not possible to separately analyze the data on central apnea index in addition to the overall $\mathrm{AHI}$, and this is because not many studies included in this network meta-analysis reported this index separately.

This network meta-analysis evaluated the comparative efficacy of only four selected treatment comparisons and while it shows superior efficacy of ASV in AHI reduction in patients with HFrEF with CSA with LVEF $<50 \%$, use of ASV especially in those with LVEF $<45 \%$ is currently contraindicated due to the findings of SERV-HF trial that showed an absolute annual risk of cardiovascular death of $10 \%$ in patients with HFrEF-CSA who were randomized to ASV vs. 7.5\% in those who were in the control group. [12] The results of the much-awaited ADVENT-HF trial may provide more clarity on future use of ASV in this particular population.[30] Two meta-analyses have shown conflicting results on the effects of ASV on LVEF- one showing that while ASV significantly reduced AHI, the effects on LVEF improvement were not significant[31] and the other showing significant improvement in LVEF with ASV as compared to control.[32] This network meta-analysis did not evaluate the comparative efficacy of treatments on LVEF improvement primarily because no such data was available from the included study on TPNS[21] and hence impossible to form a 'network' with other interventions in a network meta-analysis. Additionally, given the different follow-up durations of the various interventions in this network meta-analysis, a 6month data of LVEF changes from TPNS would conceivably not have been a fair assessment when compared to others in the network meta-analysis, primarily because a period of approximately 3 months is needed to optimally titrate nerve 'stimulation'[29] and therefore one would not expect LV remodeling to be evident until after 6 months of maximum active therapy or in other words after $9-12$ months of 
randomization. Furthermore, while ASV, BPAP-BUR and CPAP interventions in this network meta-analysis treated both central and obstructive apneas and hypopneas, given that TPNS only addresses central apneas, an assessment of LVEF function in a network meta-analysis would not be reasonable. Even so, while the 'remede System' pivotal trial[21] did not report the 6-month data on LVEF changes, it is reassuring to know that the 12-month [29] and 36-month [33] data did show small but significant improvements in LVEF compared to baseline. Furthermore, while there are issues of some sort with other interventions, like device safety issues with ASV in CSA patients with low LVEF[12], and in general poor adherence with any PAP (CPAP or BPAP), the overall safety profile of TPNS as shown in the 36 months follow-up is quite promising.[33] While the debate continues- whether CSA-CSR is a friend or foe in HF patients and that perhaps the hyperventilation during CSR may actually be protective in these patients[3436], one theory on the possible physiological links between ASV and the noted cardiovascular adverse outcomes in SERV-HF trial, that has gained much attention relates to the possible effects of high PAP on intrathoracic pressure and downstream effects. Accordingly, high PAP leads to high intrathoracic pressure, in turn leading to decrease in venous return, decreasing thereby the right ventricular stroke volume and consequently decreasing LV filling and cardiac output and eventually tipping the sympathovagal balance in these HF patients to the sympathetic side, which can be deleterious to HF patients.[37] A recent proof-of-concept study showed that neither nocturnal CPAP nor ASV favorably altered the sympathetic tone at night in CSA patients with systolic HF and patients on ASV had a significantly lower $\mathrm{Cl}$ as compared to those on CPAP.[38] Not only that, but another recent study [39] showed that use of ASV in these patients significantly decreased N3 sleep (during which vagal tone predominates) and significantly increased REM (during which sympathetic nervous activity is known to be highest or close to wakefulness activity) and N2 sleep (during which burst of sympathetic activity have been known to occur). In this context, the mechanism of action of phrenic nerve stimulation is different and opposite to that of ASV, in that while ASV increases intrathoracic pressure by PAP, TPNS via neurostimulation triggers normal breathing via diaphragmatic contraction and thus generates negative intrathoracic pressure, thereby favoring venous return to the heart.[29]

There are several limitations to this network meta-analysis. This network meta-analysis was limited in that it could not evaluate other outcomes of interest such quality-of-life metrics, or changes in LVEF, or mortality with each intervention. However as explained earlier, without having all included studies report data in similar units, one cannot create a 'network' in a network meta-analysis to analyze comparative efficacies or effectiveness of interventions specifically with regards to quality-of-life outcomes and LVEF. Analysis of mortality or other long term adverse outcomes was outside the scope of this network meta-analysis which primarily aimed at analyzing the efficacy of interventions and included studies with follow up data not long enough to be able to compute any meaningful data on such outcomes. Furthermore, the control groups in the included RCTs, which were used as common comparator or reference in the network meta-analysis, were regarded as 'GDMT', however, it is possible that the medical therapy may have varied in its composition in different studies over time as the guidelines evolved. Lastly, and most importantly a strict inclusion criteria in this network meta-analysis limited the number of studies in each intervention category and the efficacy data on TPNS is derived from 
only one RCT.[21] Nevertheless, this is the first network meta-analysis to our knowledge assessing the comparative efficacy of all interventions in CSA patients with HFrEF.

In conclusion, this network meta-analysis suggests that both TPNS and ASV are superior to other interventions in managing sleep-disordered breathing in CSA patients with HFrEF and that TPNS therapy as opposed to other interventions can also improve subjective daytime sleepiness in these patients. This network meta-analysis may have to be updated when the results of ADVENT-HF trial[30] are published.

\section{Declarations}

Funding: This study was not sponsored by any funding agency or pharmaceutical company.

Conflicts of interests: $\mathrm{II}$ reports no conflicts of interest. RNK has received consulting fees in 2018 from Respicardia Inc, a company that manufactures a transvenous phrenic nerve stimulator; and consulting fees in 2020 from Philips Respironics, a company that manufactures positive airway pressure devices.

Availability of data and material: not applicable

Code availability: not applicable

Author contributions: $\mathrm{IHI}$ had full access to all extracted data in the network meta-analysis and takes responsibility for the integrity of the data and the accuracy of the data analysis. IHI and RNK contributed to assessment of study quality, the interpretation of analyses and in revisions of manuscript.

Ethics approval: not applicable

Consent to participate: not applicable

Consent for publication: not applicable

\section{References}

1. Costanzo MR, Khayat R, Ponikowski P, Augostini R, Stellbrink C, Mianulli M, Abraham WT (2015) Mechanisms and clinical consequences of untreated central sleep apnea in heart failure. J Am Coll Cardiol 65 (1):72-84. doi:10.1016/j.jacc.2014.10.025

2. Oldenburg O, Lamp B, Faber L, Teschler H, Horstkotte D, Topfer V (2007) Sleep-disordered breathing in patients with symptomatic heart failure: a contemporary study of prevalence in and characteristics of 700 patients. Eur J Heart Fail 9 (3):251-257. doi:10.1016/j.ejheart.2006.08.003

3. Xie A, Skatrud JB, Puleo DS, Rahko PS, Dempsey JA (2002) Apnea-hypopnea threshold for CO2 in patients with congestive heart failure. Am J Respir Crit Care Med 165 (9):1245-1250.

doi:10.1164/rccm.200110-0220C

4. Brunner-La Rocca HP, Esler MD, Jennings GL, Kaye DM (2001) Effect of cardiac sympathetic nervous activity on mode of death in congestive heart failure. Eur Heart J 22 (13):1136-1143. 
doi:10.1053/euhj.2000.2407

5. Triposkiadis F, Karayannis G, Giamouzis G, Skoularigis J, Louridas G, Butler J (2009) The sympathetic nervous system in heart failure physiology, pathophysiology, and clinical implications. $J$ Am Coll Cardiol 54 (19):1747-1762. doi:10.1016/j.jacc.2009.05.015

6. Yancy CW, Jessup M, Bozkurt B, Butler J, Casey DE, Jr., Colvin MM, Drazner MH, Filippatos GS, Fonarow GC, Givertz MM, Hollenberg SM, Lindenfeld J, Masoudi FA, McBride PE, Peterson PN, Stevenson LW, Westlake C (2017) 2017 ACC/AHA/HFSA Focused Update of the 2013 ACCF/AHA Guideline for the Management of Heart Failure: A Report of the American College of Cardiology/American Heart Association Task Force on Clinical Practice Guidelines and the Heart Failure Society of America. J Am Coll Cardiol 70 (6):776-803. doi:10.1016/j.jacc.2017.04.025

7. Dark DS, Pingleton SK, Kerby GR, Crabb JE, Gollub SB, Glatter TR, Dunn MI (1987) Breathing pattern abnormalities and arterial oxygen desaturation during sleep in the congestive heart failure syndrome. Improvement following medical therapy. Chest 91 (6):833-836. doi:10.1378/chest.91.6.833

8. Walsh JT, Andrews R, Starling R, Cowley AJ, Johnston ID, Kinnear WJ (1995) Effects of captopril and oxygen on sleep apnoea in patients with mild to moderate congestive cardiac failure. $\mathrm{Br}$ Heart $\mathrm{J} 73$ (3):237-241. doi:10.1136/hrt.73.3.237

9. Javaheri S (2006) Acetazolamide improves central sleep apnea in heart failure: a double-blind, prospective study. Am J Respir Crit Care Med 173 (2):234-237. doi:10.1164/rccm.200507-10350C

10. Javaheri S, Parker TJ, Wexler L, Liming JD, Lindower P, Roselle GA (1996) Effect of theophylline on sleep-disordered breathing in heart failure. N Engl J Med 335 (8):562-567.

doi:10.1056/NEJM199608223350805

11. Costanzo MR (2020) Central Sleep Apnea in Patients with Heart Failure-How to Screen, How to Treat. Curr Heart Fail Rep 17 (5):277-287. doi:10.1007/s11897-020-00472-0

12. Cowie MR, Woehrle H, Wegscheider K, Angermann C, d'Ortho MP, Erdmann E, Levy P, Simonds AK, Somers VK, Zannad F, Teschler H (2015) Adaptive Servo-Ventilation for Central Sleep Apnea in Systolic Heart Failure. N Engl J Med 373 (12):1095-1105. doi:10.1056/NEJMoa1506459

13. Hutton B, Salanti G, Caldwell DM, Chaimani A, Schmid CH, Cameron C, loannidis JP, Straus S, Thorlund K, Jansen JP, Mulrow C, Catala-Lopez F, Gotzsche PC, Dickersin K, Boutron I, Altman DG, Moher D (2015) The PRISMA extension statement for reporting of systematic reviews incorporating network meta-analyses of health care interventions: checklist and explanations. Ann Intern Med 162 (11):777-784. doi:10.7326/M14-2385

14. Voigt J, Emani S, Gupta S, Germany R, Khayat R (2020) Meta-Analysis Comparing Outcomes of Therapies for Patients With Central Sleep Apnea and Heart Failure With Reduced Ejection Fraction. Am J Cardiol 127:73-83. doi:10.1016/j.amjcard.2020.04.011

15. Iftikhar IH, Greer M, Wigger GW, Collop NA (2020) A network meta-analysis of different positive airway pressure interventions in obesity hypoventilation syndrome. J Sleep Res:e13158. doi: $10.1111 /$ jsr. 13158 
16. Iftikhar IH, Schimmel M, Sardi A, Mehta I, Gonzalez E, Musani Al (2020) Bronchoscopic Lung Volume Reduction with Valves and Coils. A Network Meta-analysis. Ann Am Thorac Soc 17 (11):1468-1475. doi:10.1513/AnnalsATS.202002-1510C

17. Rucker G, Schwarzer G (2015) Ranking treatments in frequentist network meta-analysis works without resampling methods. BMC Med Res Methodol 15:58. doi:10.1186/s12874-015-0060-8

18. Higgins JP, Thompson SG, Deeks JJ, Altman DG (2003) Measuring inconsistency in meta-analyses. BMJ 327 (7414):557-560. doi:10.1136/bmj.327.7414.557

19. Chaimani A, Salanti G (2012) Using network meta-analysis to evaluate the existence of small-study effects in a network of interventions. Res Synth Methods 3 (2):161-176. doi:10.1002/jrsm. 57

20. Bradley TD, Logan AG, Kimoff RJ, Series F, Morrison D, Ferguson K, Belenkie I, Pfeifer M, Fleetham J, Hanly P, Smilovitch M, Tomlinson G, Floras JS, Investigators C (2005) Continuous positive airway pressure for central sleep apnea and heart failure. N Engl J Med 353 (19):2025-2033. doi:10.1056/NEJMoa051001

21. Costanzo MR, Ponikowski P, Javaheri S, Augostini R, Goldberg L, Holcomb R, Kao A, Khayat RN, Oldenburg O, Stellbrink C, Abraham WT, remede System Pivotal Trial Study G (2016) Transvenous neurostimulation for central sleep apnoea: a randomised controlled trial. Lancet 388 (10048):974982. doi:10.1016/S0140-6736(16)30961-8

22. Fietze I, Blau A, Glos M, Theres H, Baumann G, Penzel T (2008) Bi-level positive pressure ventilation and adaptive servo ventilation in patients with heart failure and Cheyne-Stokes respiration. Sleep Med 9 (6):652-659. doi:10.1016/j.sleep.2007.09.008

23. Granton JT, Naughton MT, Benard DC, Liu PP, Goldstein RS, Bradley TD (1996) CPAP improves inspiratory muscle strength in patients with heart failure and central sleep apnea. Am J Respir Crit Care Med 153 (1):277-282. doi:10.1164/ajrccm.153.1.8542129

24. Kasai T, Kasagi S, Maeno K, Dohi T, Kawana F, Kato M, Naito R, Ishiwata S, Ohno M, Yamaguchi T, Narui K, Momomura S (2013) Adaptive servo-ventilation in cardiac function and neurohormonal status in patients with heart failure and central sleep apnea nonresponsive to continuous positive airway pressure. JACC Heart Fail 1 (1):58-63. doi:10.1016/j.jchf.2012.11.002

25. Kohnlein T, Welte T, Tan LB, Elliott MW (2002) Assisted ventilation for heart failure patients with Cheyne-Stokes respiration. Eur Respir J 20 (4):934-941. doi:10.1183/09031936.00.02622001

26. Naughton MT, Liu PP, Bernard DC, Goldstein RS, Bradley TD (1995) Treatment of congestive heart failure and Cheyne-Stokes respiration during sleep by continuous positive airway pressure. Am J Respir Crit Care Med 151 (1):92-97. doi:10.1164/ajrccm.151.1.7812579

27. O'Connor CM, Whellan DJ, Fiuzat M, Punjabi NM, Tasissa G, Anstrom KJ, Benjafield AV, Woehrle H, Blase AB, Lindenfeld J, Oldenburg O (2017) Cardiovascular Outcomes With Minute VentilationTargeted Adaptive Servo-Ventilation Therapy in Heart Failure: The CAT-HF Trial. J Am Coll Cardiol 69 (12):1577-1587. doi:10.1016/j.jacc.2017.01.041

28. Philippe $C$, Stoica-Herman M, Drouot $X$, Raffestin B, Escourrou P, Hittinger L, Michel PL, Rouault $S$, d'Ortho MP (2006) Compliance with and effectiveness of adaptive servoventilation versus 
continuous positive airway pressure in the treatment of Cheyne-Stokes respiration in heart failure over a six month period. Heart 92 (3):337-342. doi:10.1136/hrt.2005.060038

29. Costanzo MR, Ponikowski P, Coats A, Javaheri S, Augostini R, Goldberg LR, Holcomb R, Kao A, Khayat RN, Oldenburg O, Stellbrink C, McKane S, Abraham WT, remede System Pivotal Trial Study G (2018) Phrenic nerve stimulation to treat patients with central sleep apnoea and heart failure. Eur J Heart Fail 20 (12):1746-1754. doi:10.1002/ejhf.1312

30. Lyons OD, Floras JS, Logan AG, Beanlands R, Cantolla JD, Fitzpatrick M, Fleetham J, John Kimoff R, Leung RS, Lorenzi Filho G, Mayer P, Mielniczuk L, Morrison DL, Ryan CM, Series F, Tomlinson GA, Woo A, Arzt M, Parthasarathy S, Redolfi S, Kasai T, Parati G, Delgado DH, Bradley TD, Investigators A$H$ (2017) Design of the effect of adaptive servo-ventilation on survival and cardiovascular hospital admissions in patients with heart failure and sleep apnoea: the ADVENT-HF trial. Eur J Heart Fail 19 (4):579-587. doi:10.1002/ejhf.790

31. Hernandez AV, Jeon A, Denegri-Galvan J, Ortega-Loayza F, Felix-Moscoso M, Pasupuleti V, Kaw R (2020) Use of adaptive servo ventilation therapy as treatment of sleep-disordered breathing and heart failure: a systematic review and meta-analysis. Sleep Breath 24 (1):49-63. doi:10.1007/s11325019-01882-8

32. Schwarz El, Scherff F, Haile SR, Steier J, Kohler M (2019) Effect of Treatment of Central Sleep Apnea/Cheyne-Stokes Respiration on Left Ventricular Ejection Fraction in Heart Failure: A Network Meta-Analysis. J Clin Sleep Med 15 (12):1817-1825. doi:10.5664/jcsm.8092

33. Fox H, Oldenburg O, Javaheri S, Ponikowski P, Augostini R, Goldberg LR, Stellbrink C, McKane S, Meyer TE, Abraham WT, Costanzo MR (2019) Long-term efficacy and safety of phrenic nerve stimulation for the treatment of central sleep apnea. Sleep 42 (11). doi:10.1093/sleep/zsz158

34. Naughton MT (2012) Cheyne-Stokes respiration: friend or foe? Thorax 67 (4):357-360. doi:10.1136/thoraxjnl-2011-200927

35. Oldenburg O, Spiesshofer J, Fox H, Bitter T, Horstkotte D (2015) Cheyne-Stokes respiration in heart failure: friend or foe? Hemodynamic effects of hyperventilation in heart failure patients and healthy volunteers. Clin Res Cardiol 104 (4):328-333. doi:10.1007/s00392-014-0784-1

36. Yasuma $F$ (2013) Is Cheyne-Stokes respiration friend or foe of heart failure? Thorax 68 (1):106-107. doi:10.1136/thoraxjnl-2012-202725

37. Joseph S, Costanzo MR (2016) A novel therapeutic approach for central sleep apnea: Phrenic nerve stimulation by the remede(R) System. Int J Cardiol 206 Suppl:S28-34.

doi:10.1016/j.ijcard.2016.02.121

38. Gorbachevski M, Spiesshoefer J, Arzt M, Oldenburg O, Becker S, Tuleta I, Emdin M, Passino C, Sciarrone P, Boentert M, Giannoni A (2020) Adaptive servo-ventilation therapy does not favourably alter sympatho-vagal balance in sleeping patients with systolic heart failure and central apnoeas: Preliminary data. Int J Cardiol 315:59-66. doi:10.1016/j.ijcard.2020.03.078

39. Roder F, Wellmann B, Bitter T, Fox H, Turoff A, Spiesshoefer J, Tamisier R, Horstkotte D, Oldenburg 0 (2020) Sleep duration and architecture during ASV for central sleep apnoea in systolic heart failure. 
Tables

TABLE 1:

\begin{tabular}{|c|c|c|c|c|c|c|c|}
\hline & Age & $\begin{array}{l}\text { Gender } \\
\text { (male\%) }\end{array}$ & BMI & $\begin{array}{l}\text { Follow up } \\
\text { duration (for } \\
\text { network meta- } \\
\text { analysis) }\end{array}$ & AHI & LVEF & $\begin{array}{l}\text { PAP adherence } \\
\text { (hours/night) }\end{array}$ \\
\hline $\begin{array}{l}\mathrm{PAP}=128 \\
\mathrm{DMT}=130\end{array}$ & $\begin{array}{l}\mathrm{CPAP}= \\
63.2 \pm 9.1 \\
\mathrm{GDMT}= \\
63.5 \pm 9.8\end{array}$ & $\begin{array}{l}\text { CPAP = } \\
98 \% \\
\text { GDMT = } \\
95 \%\end{array}$ & $\begin{array}{l}\text { CPAP }= \\
28.8 \pm 5.5 \\
\text { GDMT = } \\
29.3 \pm 6.5\end{array}$ & 24 months & $\begin{array}{l}\text { CPAP = } \\
40 \pm 15 \\
\text { GDMT = } \\
40 \pm 17\end{array}$ & $\begin{array}{l}\mathrm{CPAP}= \\
24.8 \pm 7.9 \\
\mathrm{GDMT}= \\
24.2 \pm 7.6\end{array}$ & 3.6 to 4.3 \\
\hline $\begin{array}{l}? \mathrm{NS}=73 \\
\mathrm{DMT}=78\end{array}$ & $\begin{array}{l}\text { TPNS = } \\
65 \pm 12 \\
\text { GDMT = } \\
65 \pm 13\end{array}$ & $\begin{array}{l}\text { TPNS = } \\
86 \% \\
\text { GDMT = } \\
92 \%\end{array}$ & $\begin{array}{l}\text { TPNS = } \\
30.8 \pm 5.3 \\
\text { GDMT }= \\
31.3 \pm 6.6\end{array}$ & 6 months & $\begin{array}{l}\text { TPNS }= \\
48.8 \pm 19.3 \\
\text { GDMT }= \\
43.7 \pm 16.8\end{array}$ & $\begin{array}{l}\text { TPNS = } \\
39.7 \pm 12.1 \\
\text { GDMT }= \\
39.4 \pm 12.2\end{array}$ & N/A \\
\hline $\begin{array}{l}\mathrm{SV}=17 \\
\mathrm{PAP}-\mathrm{ST}=20\end{array}$ & $\begin{array}{l}\mathrm{ASV}= \\
61.9 \pm 9.1 \\
\text { BPAP-ST } \\
=56.4 \pm \\
10.9\end{array}$ & $\begin{array}{l}\text { ASV = } \\
88 \% \\
\text { BPAP- } \\
\text { ST = } \\
95 \%\end{array}$ & $\begin{array}{l}\mathrm{ASV}= \\
26.9 \pm \\
2.4 \\
\text { BPAP-ST } \\
=28.9 \pm \\
4.8\end{array}$ & 6 weeks & $\begin{array}{l}\text { ASV }= \\
31.7 \pm \\
9.8^{*} \\
\text { BPAP-ST } \\
=34.9 \pm \\
20.4^{*}\end{array}$ & $\begin{array}{l}\mathrm{ASV}= \\
24.6 \pm 7.9 \\
\text { BPAP-ST }= \\
25.5 \pm 9.2\end{array}$ & N.R \\
\hline $\begin{array}{l}\mathrm{PAP}=9 \\
\mathrm{DMT}=8\end{array}$ & $\begin{array}{l}\mathrm{CPAP}= \\
58.3 \pm 2.2 \\
\mathrm{GDMT}= \\
58.0 \pm 2.0\end{array}$ & N.R & $\begin{array}{l}\mathrm{CPAP}= \\
28.9 \pm \\
1.9 \\
\mathrm{GDMT}= \\
25.4 \pm \\
1.8\end{array}$ & 3 months & $\begin{array}{l}\text { CPAP = } \\
49 \pm 11 \\
\text { GDMT = } \\
35 \pm 11\end{array}$ & $\begin{array}{l}\mathrm{CPAP}= \\
24.0 \pm 4.0 \\
\mathrm{GDMT}= \\
20.6 \pm 3.2\end{array}$ & $5.6 \pm 0.7$ \\
\hline $\begin{array}{l}\mathrm{SV}=12 \\
\mathrm{PAP}=11\end{array}$ & $\begin{array}{l}\mathrm{ASV}= \\
64.3 \pm 8.8 \\
\mathrm{CPAP}= \\
65.8 \pm 8.7\end{array}$ & N.R & $\begin{array}{l}\mathrm{ASV}= \\
26.3 \pm 4.2 \\
\mathrm{CPAP}= \\
26.9 \pm 5.2\end{array}$ & 3 months & $\begin{array}{l}\mathrm{ASV}= \\
25.0 \pm 6.9 \\
\mathrm{CPAP}= \\
23.0 \pm 7.9\end{array}$ & $\begin{array}{l}\mathrm{ASV}= \\
32.0 \pm 7.9 \% \\
\mathrm{CPAP}= \\
32.9 \pm 5.9 \%\end{array}$ & $\begin{array}{l}\mathrm{ASV}=4.7 \pm 0.6 \\
\mathrm{CPAP}=3.3 \pm 1.2\end{array}$ \\
\hline $\begin{array}{l}\text { os patients randomized in a } \\
\text { osser design to each } \\
\text { tervention }\end{array}$ & $62.0 \pm 7.4$ & $81 \%$ & $27.3 \pm 3.2$ & $\begin{array}{l}14 \text { days on each } \\
\text { intervention }\end{array}$ & $26.7 \pm 10.7$ & $23.8 \pm 6.5$ & $\begin{array}{l}\text { BPAP-BUR } \\
=5.1 \pm 1.5 \\
\text { CPAP }=5.6 \pm 1.5\end{array}$ \\
\hline $\begin{array}{l}\mathrm{PAP}=12 \\
\mathrm{DMT}=12\end{array}$ & $\begin{array}{l}\mathrm{CPAP}= \\
61.0 \pm 3.2 \\
\mathrm{GDMT}= \\
56.6 \pm 3.2\end{array}$ & N.R & $\begin{array}{l}\mathrm{CPAP}= \\
26.0 \pm \\
1.5 \\
\mathrm{GDMT}= \\
27.1 \pm \\
1.5\end{array}$ & 3 months & $\begin{array}{l}\mathrm{CPAP}= \\
43.2 \pm 4.9 \\
\text { GDMT }= \\
33.1 \pm 7.1\end{array}$ & $\begin{array}{l}\mathrm{CPAP}= \\
21.2 \pm 3.8 \\
\mathrm{GDMT}= \\
19.7 \pm 2.7\end{array}$ & $\mathrm{CPAP}=5.9 \pm 0.6$ \\
\hline $\begin{array}{l}\mathrm{SV}=65 \\
\mathrm{DMT}=61\end{array}$ & $\begin{array}{l}\mathrm{ASV}= \\
61 \pm 14 \\
\mathrm{GDMT}= \\
63 \pm 13\end{array}$ & $\begin{array}{l}\text { ASV = } \\
75 \% \\
\text { GDMT = } \\
72 \%\end{array}$ & $\begin{array}{l}\mathrm{ASV}= \\
32.3 \pm 9.0 \\
\mathrm{GDMT}= \\
31.4 \pm 8.6\end{array}$ & 6 months & $\begin{array}{l}\mathrm{ASV}= \\
35.7 \pm 17.1 \\
\mathrm{GDMT}= \\
35.1 \pm 16.7\end{array}$ & $\begin{array}{l}\mathrm{ASV}= \\
30.5 \pm 15.4 \\
\mathrm{GDMT}= \\
33.7 \pm 15.7\end{array}$ & 2.7 average \\
\hline $\begin{array}{l}\mathrm{SV}=12 \\
\mathrm{PAP}=13\end{array}$ & $\begin{array}{l}\mathrm{ASV}= \\
64.2 \pm 15.5 \\
\mathrm{CPAP}= \\
60.3 \pm 11.5\end{array}$ & $\begin{array}{l}\mathrm{ASV}= \\
100 \% \\
\mathrm{CPAP}= \\
100 \%\end{array}$ & $\begin{array}{l}\mathrm{ASV}= \\
25.2 \pm 3.3 \\
\mathrm{CPAP}= \\
28.8 \pm 6.3\end{array}$ & 6 months & $\begin{array}{l}\text { ASV }= \\
47 \pm 18.6 \\
\text { CPAP }= \\
40.5 \pm 13.9\end{array}$ & $\begin{array}{l}\mathrm{ASV}= \\
29 \pm 9 \\
\mathrm{CPAP}= \\
30 \pm 9\end{array}$ & $\begin{array}{l}4.33 .1 \\
\text { (averaged in } \\
\text { both ASV and } \\
\text { CPAP) }\end{array}$ \\
\hline
\end{tabular}




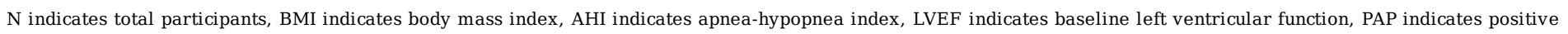

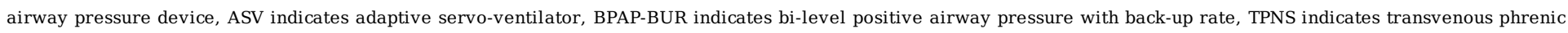

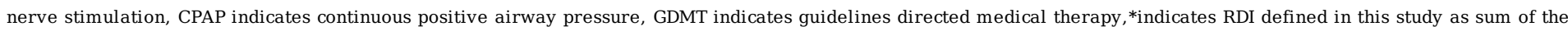

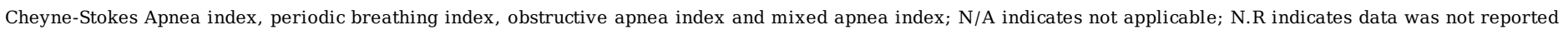

Table 2: Net League table for AHI analysis:

\begin{tabular}{|c|c|c|c|c|}
\hline \multicolumn{5}{|c|}{ NET LEAGUE TABLE FOR AHI ANALYSIS } \\
\hline ASV & - & $-2.00[-21.37 ; 17.37]$ & $-23.10[-40.89 ;-5.31]$ & $-15.80[-33.86 ; 2.26]$ \\
\hline$-1.15[-23.19 ; 20.89]$ & TPNS & - & - & $-24.90[-42.88 ;-6.92]$ \\
\hline$-5.69[-20.36 ; 8.97]$ & $-4.54[-28.68 ; 19.60]$ & BPAP-BUR & $-1.20[-19.10 ; 16.70]$ & - \\
\hline$-10.05[-22.07 ; 1.98]$ & $-8.89[-29.19 ; 11.40]$ & $-4.35[-18.62 ; 9.91]$ & CPAP & $-19.33[-29.62 ;-9.05]$ \\
\hline$-26.05[-38.80 ;-13.31]$ & $-24.90[-42.88 ;-6.92]$ & $-20.36[-36.47 ;-4.25]$ & $-16.01[-25.42 ;-6.60]$ & GDMT \\
\hline $\begin{array}{l}\text { Studies in direct pairwi } \\
\text { ASV vs BPAP-BUR }=\text { Fi } \\
\text { ASV vs CPAP = Kasai } 2 \\
\text { ASV vs GDMT = O'Conr } \\
\text { BPAP-BUR vs CPAP }=\mathrm{K} \\
\text { CPAP vs GDMT = Bradl } \\
\text { TPNS vs GDMT = Costa }\end{array}$ & $\begin{array}{l}\text { se meta-analysis compa } \\
\text { tze } 2008^{22} \\
13^{24} \\
\text { or } 2017^{27} \\
\text { hnlein } 2002^{25} \\
\text { y } 2005^{20}, \text { Granton } 1996 \\
\text { nzo } 2016^{21}\end{array}$ & Naughton $1995^{26}$ & & \\
\hline \multicolumn{5}{|c|}{$\begin{array}{l}\text { Quantifying heterogeneity / inconsistency: } \\
\operatorname{tau}^{2}=72.6 ; I^{2}=88.5 \%\end{array}$} \\
\hline \multicolumn{5}{|c|}{ Tests of heterogeneity (within designs) and inconsistency (between designs): } \\
\hline & $\mathrm{Q}$ & \multicolumn{3}{|c|}{$\mathrm{p}$ value } \\
\hline Total & 34.84 & \multicolumn{3}{|l|}{$<0.0001$} \\
\hline Within designs & 2.00 & \multicolumn{3}{|l|}{0.36} \\
\hline Between designs & 32.84 & \multicolumn{3}{|l|}{$<0.0001$} \\
\hline \multicolumn{5}{|c|}{ NET LEAGUE TABLE FOR AHI SENSITTVITY ANALYSIS } \\
\hline ASV & - & - & $-23.10[-29.22 ;-16.98]$ & - \\
\hline$-18.30[-27.81 ;-8.79]$ & TPNS & - & - & $-24.90[-31.57 ;-18.23]$ \\
\hline$-21.90[-30.79 ;-13.01]$ & $-3.60[-13.33 ; 6.12]$ & BPAP-BUR & $-1.20[-7.65 ; 5.25]$ & - \\
\hline$-23.10[-29.22 ;-16.98]$ & $-4.80[-12.08 ; 2.48]$ & $-1.20[-7.65 ; 5.25]$ & CPAP & $-20.10[-23.01 ;-17.18]$ \\
\hline$-43.20[-49.98 ;-36.42]$ & $-24.90[-31.57 ;-18.23]$ & $-21.30[-28.38 ;-14.22]$ & $-20.10[-23.01 ;-17.18]$ & GDMT \\
\hline $\begin{array}{l}\text { Studies in direct pairwi } \\
\text { ASV vs CPAP = Kasai } 2 \\
\text { BPAP-BUR vs CPAP }=\mathrm{K} \\
\text { CPAP vs GDMT }=\text { Bradl } \\
\text { TPNS vs GDMT = Costa }\end{array}$ & $\begin{array}{l}\text { se meta-analysis compa } \\
13^{24} \\
\text { hnlein } 2002^{25} \\
\text { ey } 2005^{20}, \text { Granton } 1996 \\
\text { nzo } 2016^{21}\end{array}$ & sons: & & \\
\hline \multicolumn{5}{|c|}{$\begin{array}{l}\text { Quantifying heterogeneity / inconsistency: } \\
\operatorname{tau}^{2}=0.01 ; I^{2}=0.2 \%\end{array}$} \\
\hline \multicolumn{5}{|c|}{ Tests of heterogeneity (within designs) and inconsistency (between designs): } \\
\hline & $\mathrm{Q}$ & $\mathrm{p}$ value & & \\
\hline Total & 2 & 0.36 & & \\
\hline Within designs & 2 & 0.36 & & \\
\hline Between designs & 0 & $\begin{array}{l}- \\
--\end{array}$ & & \\
\hline
\end{tabular}




\begin{tabular}{|c|c|c|c|c|}
\hline TPNS & - & $-3.70[-5.58 ;-1.82]$ & - & - \\
\hline$-3.20[-5.86 ;-0.54]$ & ASV & $-0.50[-2.38 ; 1.38]$ & $-0.70[-3.33 ; 1.93]$ & $-1.34[-3.85 ; 1.17]$ \\
\hline$-3.70[-5.58 ;-1.82]$ & $-0.50[-2.38 ; 1.38]$ & GDMT & - & - \\
\hline$-4.00[-7.33 ;-0.68]$ & $-0.80[-2.79 ; 1.19]$ & $-0.30[-3.04 ; 2.44]$ & BPAP-BUR & $-0.40[-2.14 ; 1.34]$ \\
\hline$-4.45[-7.75 ;-1.14]$ & $-1.25[-3.21 ; 0.71]$ & $-0.75[-3.47 ; 1.97]$ & $-0.45[-2.02 ; 1.13]$ & CPAP \\
\hline $\begin{array}{l}\text { Studies in direct pa } \\
\text { ASV vs BPAP-BUR }= \\
\text { ASV vs CPAP }=\text { Kas } \\
\text { ASV vs GDMT }=\mathrm{O}^{\prime} \\
\text { BPAP-BUR vs CPAP } \\
\text { TPNS vs GDMT = C }\end{array}$ & $\begin{array}{l}\text { rwise meta-analysis } \\
\text { Fietze } 2008^{22} \\
\text { i } 2013^{24}, \text { Philippe } 20 \\
\text { onnor } 2017^{27} \\
=\text { Kohnlein } 2002^{25} \\
\text { stanzo } 2016^{21}\end{array}$ & $\begin{array}{l}\text { comparisons: } \\
6^{28}\end{array}$ & & \\
\hline \multicolumn{5}{|c|}{$\begin{array}{l}\text { Quantifying heterogeneity / inconsistency: } \\
\text { tau }^{2}=0 ; I^{2}=0 \%\end{array}$} \\
\hline \multicolumn{5}{|c|}{ Tests of heterogeneity (within designs) and inconsistency (between designs): } \\
\hline & $\mathrm{Q}$ & $\mathrm{p}$ value & & \\
\hline Total & 0.09 & 0.95 & & \\
\hline Within designs & 0.07 & 0.78 & & \\
\hline Between designs & 0.01 & 0.90 & & \\
\hline
\end{tabular}

\section{Table 3: Net League table for ESS analysis}

\section{Figures}




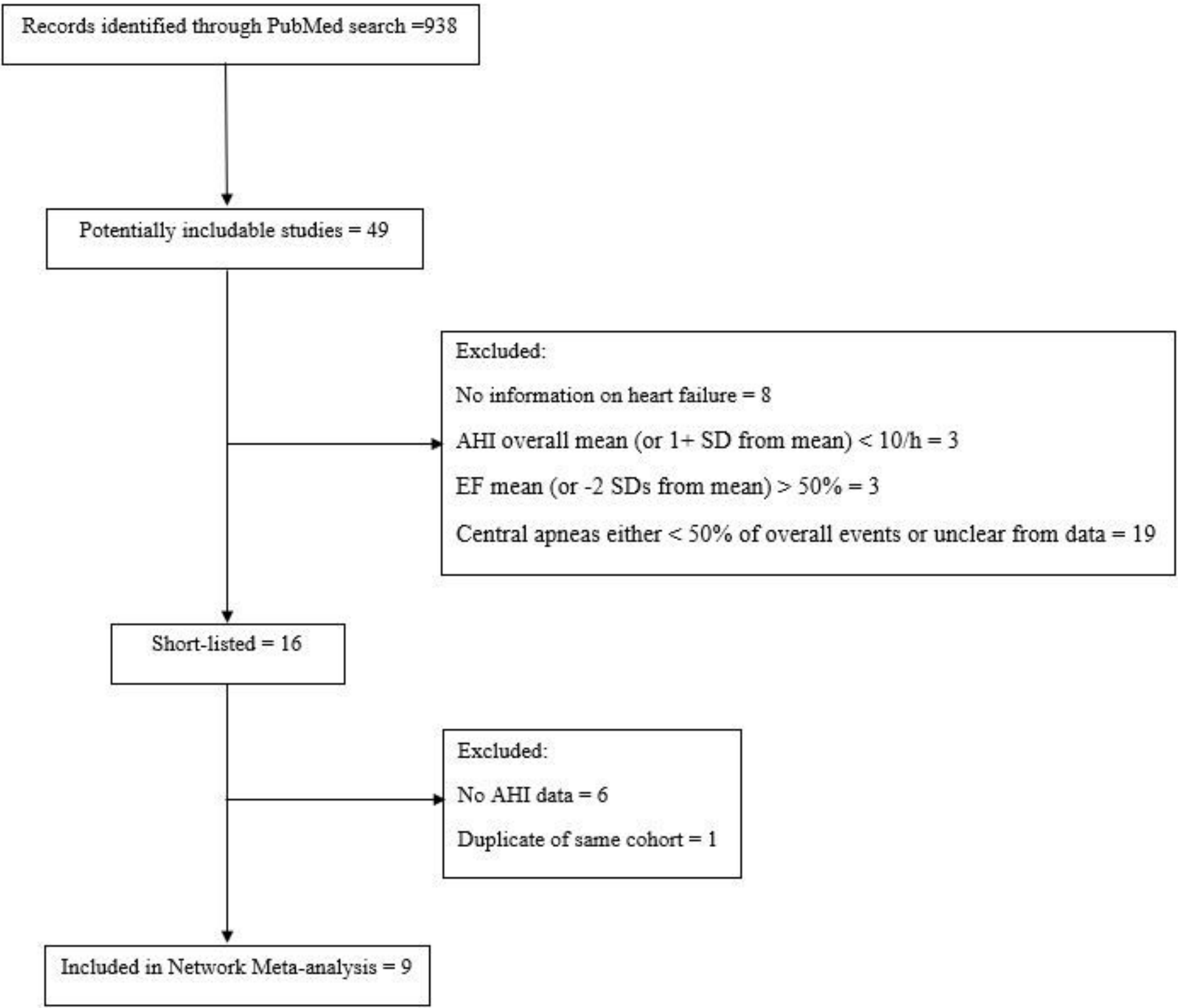

\section{Figure 1}

Search strategy and selection process 


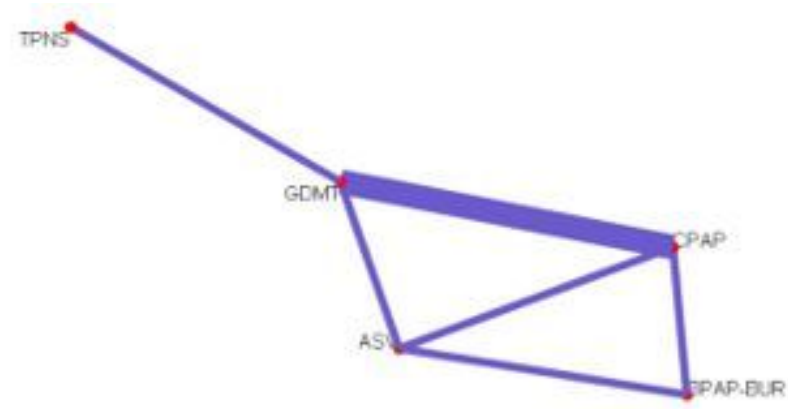

Figure 2b: AHI sensitivity analysis

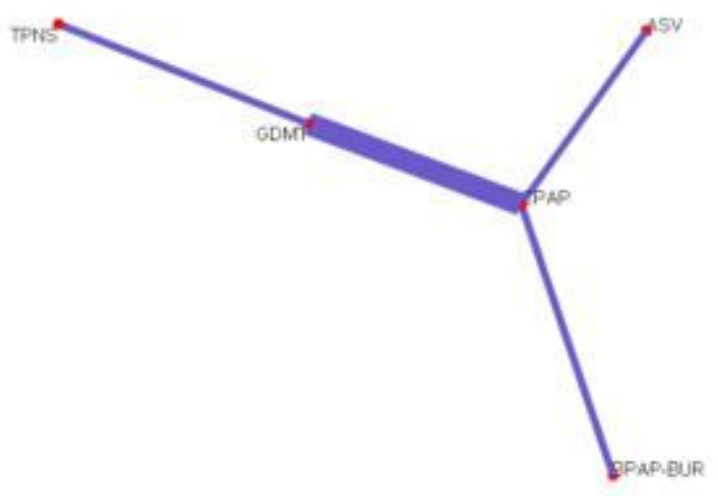

Figure 2c: ESS analysis

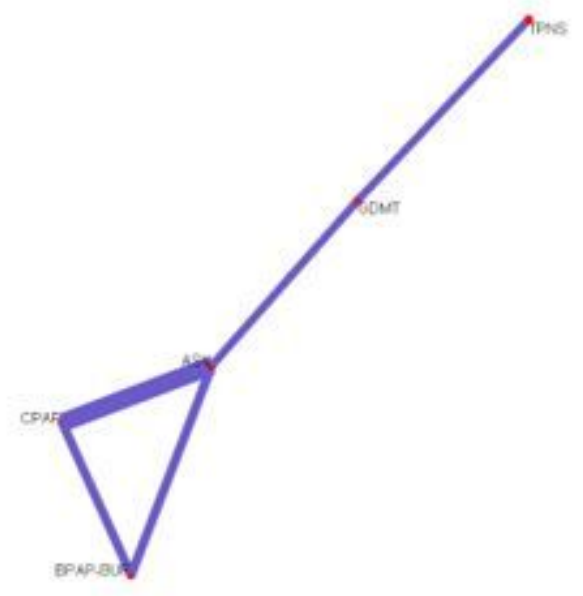

\section{Figure 2}

Network evidence plots for primary outcomes Graph plotted on a 3-dimensional plane, in which the nodes in the graph layout corresponded to the ventilatory mode and connecting lines displaying the treatment comparisons (thickness of lines indicating number of studies in each comparison). ASV indicates adaptive servo-ventilator, BPAP-BUR indicates bi-level positive airway pressure with back-up rate, TPNS indicates transvenous phrenic nerve stimulation, CPAP indicates continuous positive airway pressure, GDMT indicates guidelines directed medical therapy 
Figure 3a: Forest plot for AHI analysis

Comparison: other vs 'GDMT'

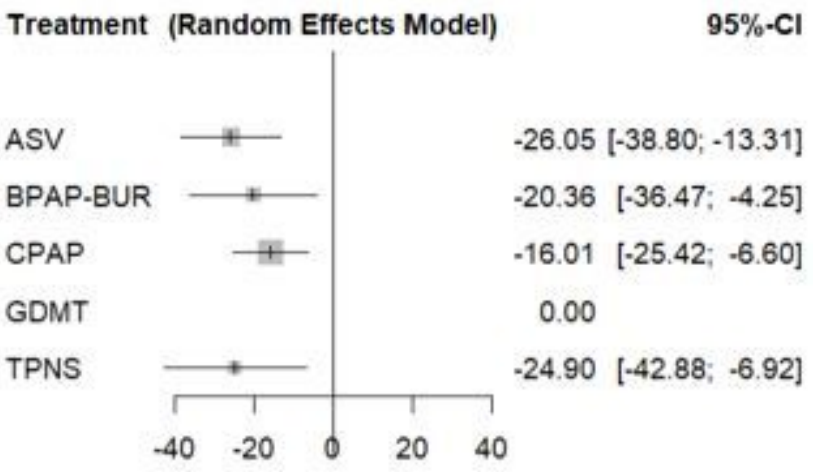

Figure 3b: Forest plot for AHI sensitivity analysis

Comparison: other vs 'GDMT'

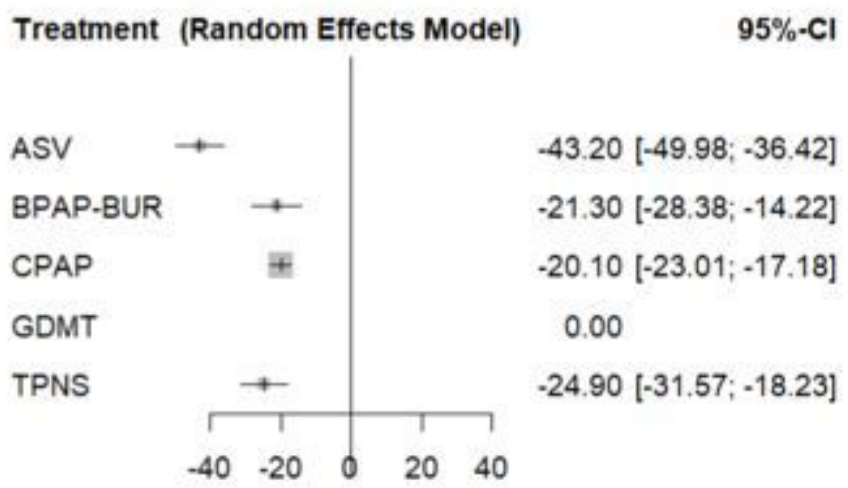

\section{Figure 3}

Network meta-analysis forest plot for $\mathrm{AHI}$ analysis The size of the square indicates the weight of the effect size as determined by the number of studies and participants. $\mathrm{Cl}$, confidence interval, $\mathrm{AHI}$ indicates apnea-hypopnea index 


\section{Comparison: other vs 'GDMT'}

\section{Treatment (Random Effects Model) \\ $95 \%-\mathrm{Cl}$}

ASV

BPAP-BUR

CPAP

GDMT

TPNS

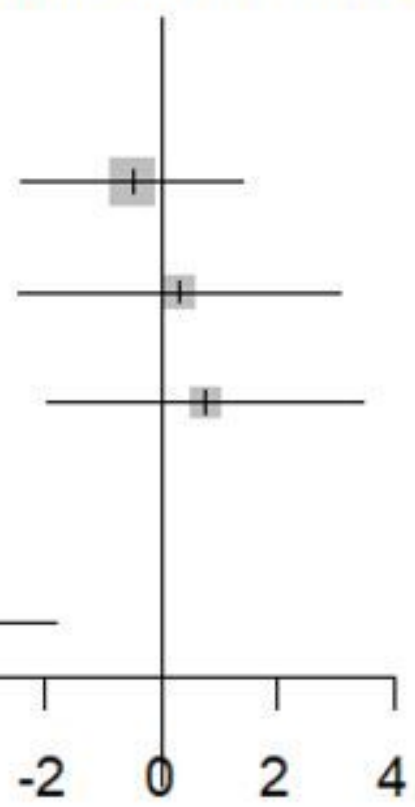

$-0.50[-2.38 ; 1.38]$

$0.30[-2.44 ; 3.04]$

$0.75[-1.97 ; 3.47]$

0.00

$-3.70[-5.58 ;-1.82]$

Figure 4

Network meta-analysis forest plot for ESS analysis The size of the square indicates the weight of the effect size as determined by the number of studies and participants. $\mathrm{Cl}$, confidence interval, ESS indicates Epworth sleepiness scale score 


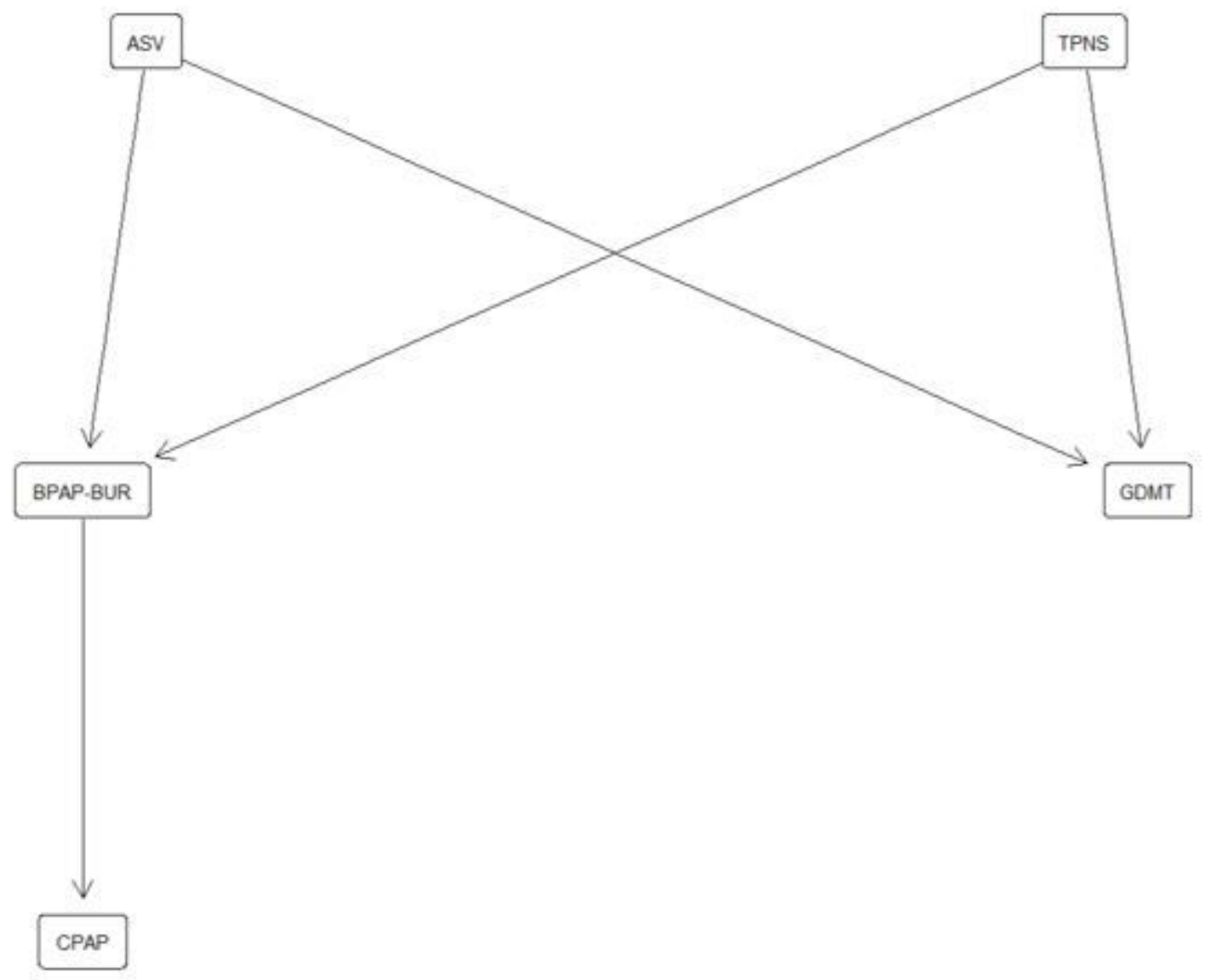

\begin{tabular}{|l|l|l|}
\hline AHI analysis & P-scores (random effects model) & Rank \\
\hline ASV & $0.81\left(1.00^{*}\right)$ & $1^{\text {s }}$ \\
\hline TPNS & $0.72\left(0.66^{*}\right)$ & $2^{\text {nI }}$ \\
\hline BPAP-BUR & $0.57\left(0.46^{*}\right)$ & $3^{\text {nIl }}$ \\
\hline CPAP & $0.38\left(0.36^{*}\right)$ & $4^{\text {th }}$ \\
\hline GDMT & $0.00\left(0.00^{*}\right)$ & $5^{\text {th }}$ \\
\hline ESS analysis & P-scores (random effects model) & Rank \\
\hline TPNS & 0.99 & $1^{\text {sh }}$ \\
\hline ASV & 0.59 & $2^{\text {nI }}$ \\
\hline GDMT & 0.39 & $3^{\text {nI }}$ \\
\hline BPAP-BUR & 0.33 & $4^{\text {th }}$ \\
\hline CPAP & 0.17 & $5^{\text {th }}$ \\
\hline
\end{tabular}

\section{Figure 5}

Ranking of treatments for primary outcomes The Hasse diagram illustrates treatment relations in a partially ordered set with superior objects located above inferior ones. The treatments on the top of the diagram have a higher overall rank than the treatments below them, with arrows pointing to the inferior treatments. The $\mathrm{P}$ score (B) represents the probability that one treatment is better than the others, with higher values (ranging from 0 to 100) corresponding to a higher ranking. *P scores in brackets are from 
AHI sensitivity analysis, the hierarchy of treatments as depicted in this figure was identical to that computed for AHI sensitivity analysis.

Figure 6a: Publication bias assessment for AHI analysis

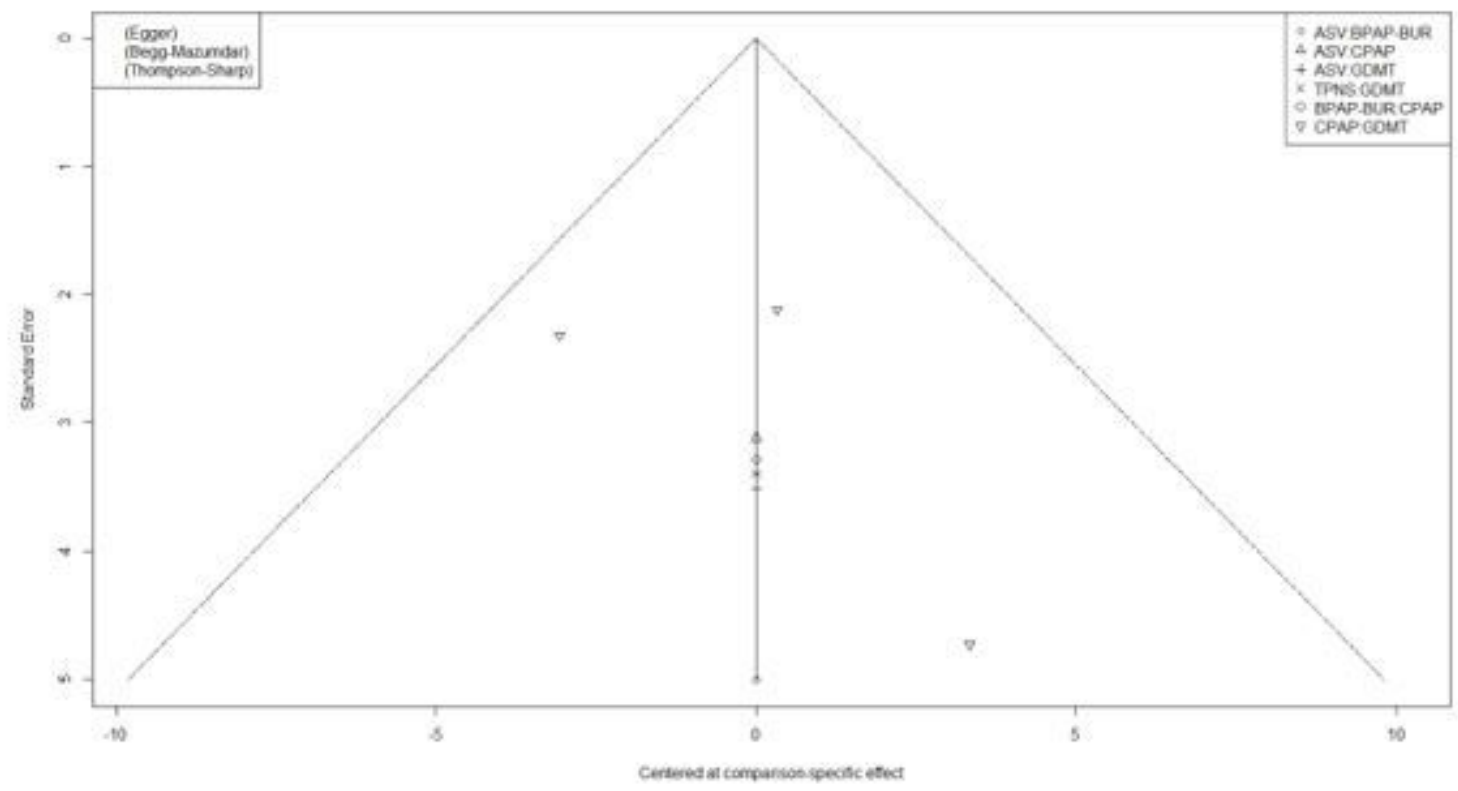

Figure 6b: Publication bias assessment for ESS analysis

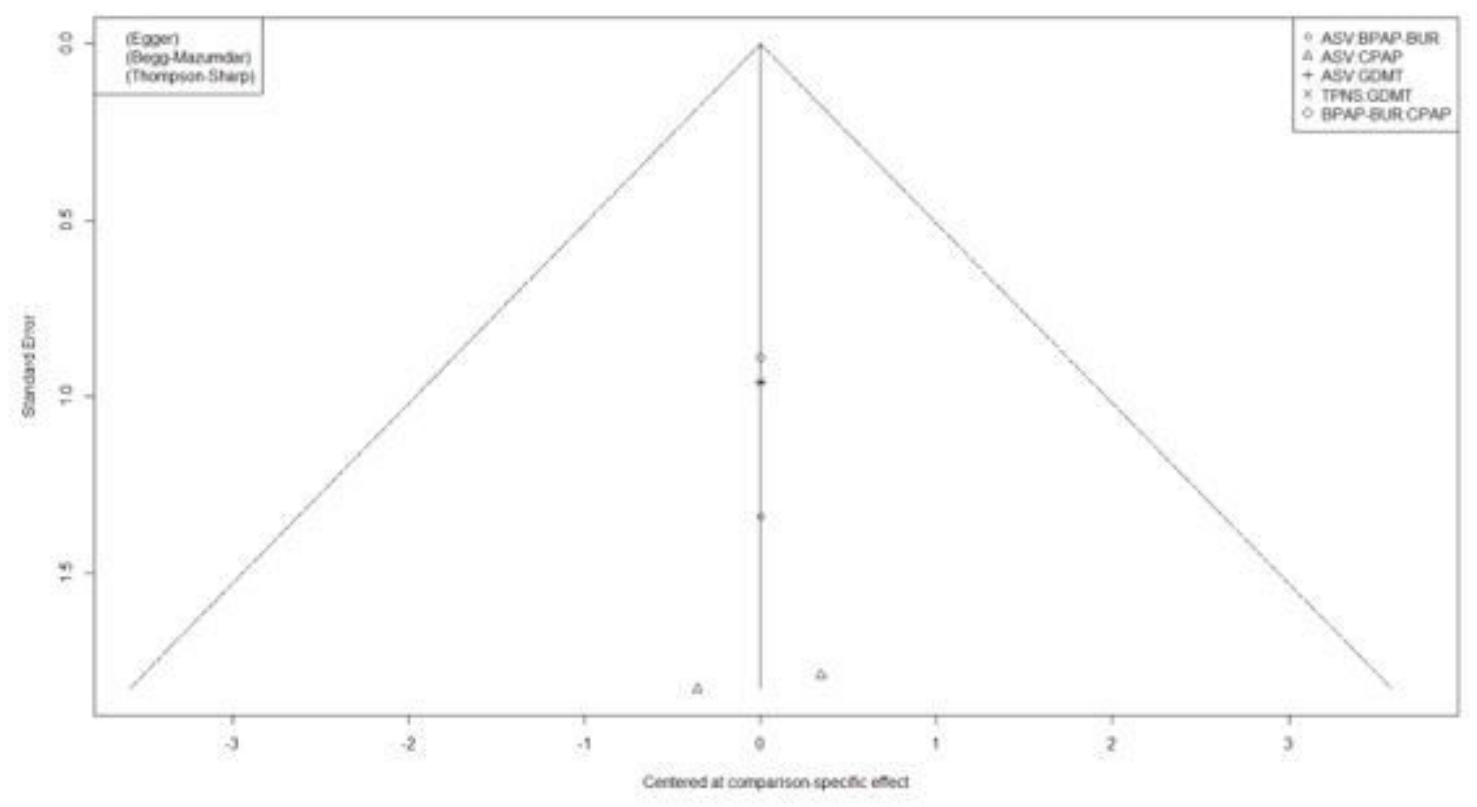

Figure 6

Comparison-adjusted funnel plots

\section{Supplementary Files}


This is a list of supplementary files associated with this preprint. Click to download.

- APPENDIX.docx 